\title{
SYSTOLIC TIME INTERVAL CHANGES AFTER AORTO-CORONARY BYPASS
}

\author{
R.J. Byrick, S.J. Teasdale, and P. Young
}

\section{INTRODUCTION}

The increasing number of aorto-coronary bypass procedures now being performed has brought to the operating room, and to the anaesthetist, patients with varying degrees of myocardial competency. This myocardial competency, or contractile performance of the heart in patients with ischaemic heart disease is likely to influence prognosis, response to anaesthetic agents, and the post-operative course.

The problem is how to assess left ventricular performance when there is no unique measurement, invasive or non-invasive, which is acceptable as an indicator of myocardial contractility. To date, probably the most useful clinical index of left ventricular function is the ejection fraction, which is the ratio of stroke volume divided by left ventricular end-diastolic volume. This is usually measured by invasive technique during angiography. Although this index is a function of initial fibre length it has been found to bear a significant relationship to the ultimate prognosis of patients undergoing aorto-coronary bypass surgery. ${ }^{1}$ Unfortunately this measurement is not readily available to the anaesthetist as a monitoring tool.

Systolic time intervals, a non-invasive measurement, has been shown to correlate well with ejection fraction and with other invasive indices of left ventricular function in man. ${ }^{2}$ These intervals are easily detectable alterations in the temporal course of the cardiac cycle which have been found to correspond to changes in heart function. For example, depressed left ventricular function in the decompensated heart produces measurable changes in systolic time intervals. Stated simplistically, during left ventricular failure the pre-ejection period lengthens, reflecting a slower rate of development of myocardial tension, while the left ventricular ejection time diminishes, the result of a smaller stroke volume due to decreased rate of myocardial fibre shortening. In this circumstance the duration of total electromechanical systole remains unchanged.

Even more useful are the changes in the ratio of the pre-ejection period to the left ventricular ejection time (PEP/LVET). This ratio has the advantages of encompassing deviations of both basic intervals, the pre-ejection period and the left ventricular ejection time, and may reflect abnormalities when neither one alone is clearly abnormal. Furthermore, the ratio is not influenced by heart rate

R.J. Byrick, M.D., Research Fellow, Department of Anaesthesia, University of Toronto, St. Michael's Hospital, Toronto, Ontario.

S.J. Teasdale, M.D., F.R.C.P.(C), Department of Anaesthesia, University of Toronto and Toronto Ceneral Hospital, Toronto, Ontario.

P. Young, R.N., Department of Anaesthesia, University of Toronto, Toronto, Ontario.

Address for Reprints: Dr. S. Teasdale, 9th Floor University Wing, Toronto General Hospital, Toronto, Ontario, M5G 1L7, Canada.

Canad. Anaesth. Soc. J., vol. 24, no. 2, March 1977 
within a range of $40-110$ beats/minute and is relatively unaffected by digitalis, which tends to shorten both intervals.

This study uses systolic time intervals to evaluate left ventricular performance in patients undergoing aorto-coronary saphenous vein bypass graft surgery. Although left ventricular dysfunction has been demonstrated post-operatively by others, ${ }^{3-5}$ the pattern and duration of this impaired myocardial performance has not been reported.

\section{Methods}

We studied 28 patients undergoing saphenous vein aorto-coronary bypass surgery. Systolic time intervals were recorded on each patient in the resting supine position as described by Weissler. ${ }^{6}$ An Elema-Scholander 8-channel recorder was used to record electrocardiogram, phonocardiogram and carotid pulse wave simultaneously. All records were made at a paper speed of $100 \mathrm{~mm}$ per second. The frequency responses of the carotid pulse recorder $(0.1-40 \mathrm{~Hz})$ and the phonocardiograph $(100-400 \mathrm{~Hz})$ were verified. The carotid pulse was recorded with a pressure cup through polyethylene tubing in series with an air-coupled transducer. An Elema-Scholander piezo-microphone with a low frequency band pass filter was used to record heart sounds. The standard electrocardiogram (lead II) was used to demonstrate the $Q$ wave, which marks the onset of electro-mechanical systole $\left(\mathrm{QS}_{2}\right)$ (Figure 1). The left ventricular ejection time (LVET) was measured from the onset of the rapid carotid upstroke to the dicrotic notch. The total electro-mechanical systole $\left(\mathrm{QS}_{2}\right)$ is the measured interval from the $Q$ wave to the first high frequency vibrations of the second heart sound (aortic valve closure). The pre-ejection period (PEP) was derived by subtracting the LVET from the $\mathrm{QS}_{2}$ (Figure 1). Each interval reported is the average of ten consecutive individually measured cardiac beats.

Each patient was studied pre-operatively to establish a control value. Subsequent measurements were made immediately following operation and each morning (0800-1000 hours) thereafter for the duration of hospitalization. The intervals PEP, LVET and $\mathrm{QS}_{2}$ were corrected for the effects of heart rate using the regression equations reported by Weissler. ${ }^{7}$ This correction yielded the various indices reported as PEPI, LVETI and $\mathrm{QS}_{2} \mathrm{I}$. The ratio $\mathrm{PEP} / \mathrm{LVET}$ needs no correction and represents the ratio of two directly measured intervals. Changes were considered significant from the control value if $P<0.05$. All values are reported as the mean \pm one standard deviation ( \pm 1 S.D.).

All patients received pantopon and hyoscine premedication, were induced with sodium thiopentone and intubated following the administration of pancuronium. Innovar, pantopon, and $\mathrm{N}_{2} \mathrm{O}: \mathrm{O}_{2}$ were used to maintain anaesthesia. A Bentley bubble oxygenator was used for all patients included in the study and moderate hypothermia (to $30^{\circ} \mathrm{C}$ ) was utilized during extracorporeal circulation.

Twenty-four ( 86 per cent) of the total group of patients were operated upon because of unstable pre-infarction angina. Of the remaining four patients, three had severe but stable angina and one had recurrent bouts of ventricular arrhythmias. Eight patients ( 29 per cent) received digoxin pre-operatively. Although 18 


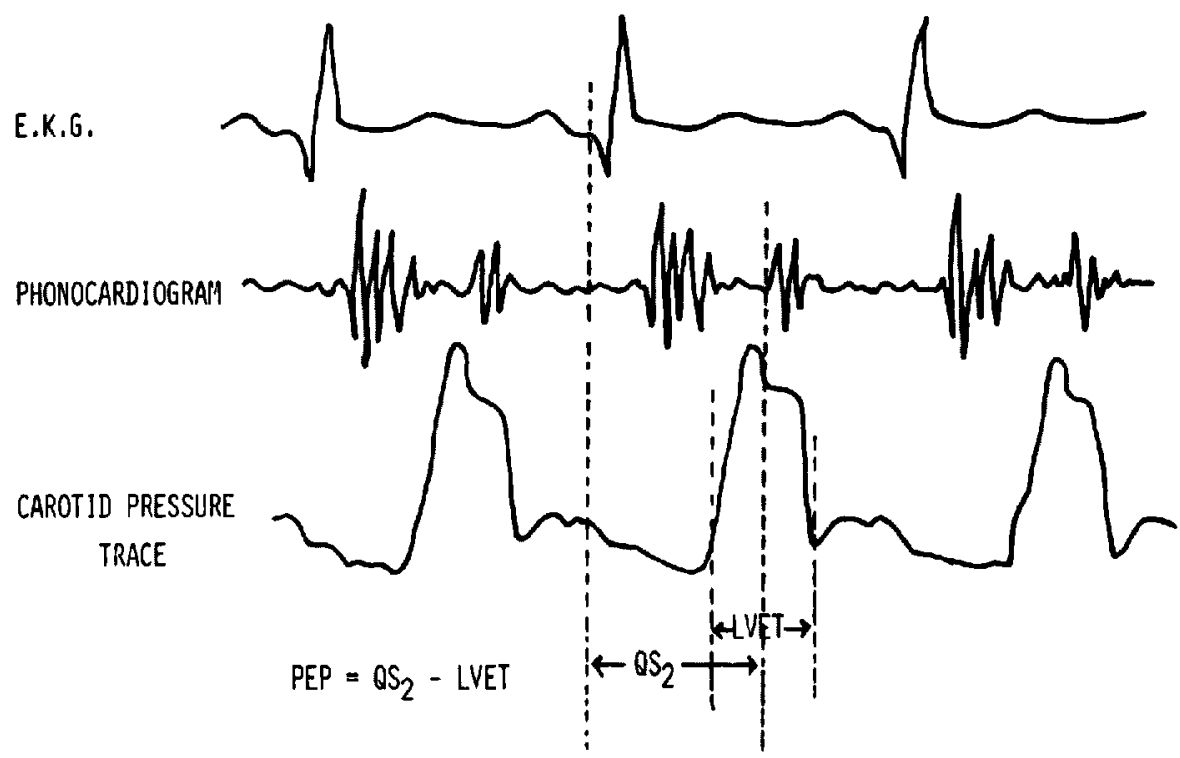

FIgure 1. Relation of systolic time intervals to the cardiac cycle. $\mathrm{PEP}=$ pre-ejection period; LVET = left ventricular ejection time; $Q S_{1}=$ total electromechanical systole.

patients had received propanolol pre-operatively this drug was discontinued in all patients 12 hours or more before commencement of surgery. Only two patients received propanolol post-operatively. All patients were in normal sinus rhythm without A.V conduction disturbances when our measurements were performed. Sixteen patients ( 57 per cent) had a history of one or more documented myocardial infarctions pre-operatively but only one was thought to have suffered a peri-operative myocardial infarction on the basis of electrocardiogram or enzyme changes.

In the second part of the study, 16 of the 28 patients were classified according to evaluation of ventricular function expressed as ejection fraction by the cardiologist during pre-operative angiography. Group A were patients who had significant coronary artery disease but normal ejection fractions, i.e. more than 60 per cent. Group B were patients with poor ventricular contractility as indicated by ejection fractions less than 60 per cent. Patients who received post-operative inotropic or mechanical assistance (intra-aortic balloon pump) were not included in this comparison study.

\section{RESULTS}

\section{Pattern of PEP/LVET changes}

The mean control value of PEP/LVET for all 28 patients is abnormal. Significantly impaired ventricular performance as shown by an elevation of the PEP/ LVET ratio is most marked immediately post-operatively and persists until the fifth post-operative day. The change in PEP/LVET from control to the immediate 


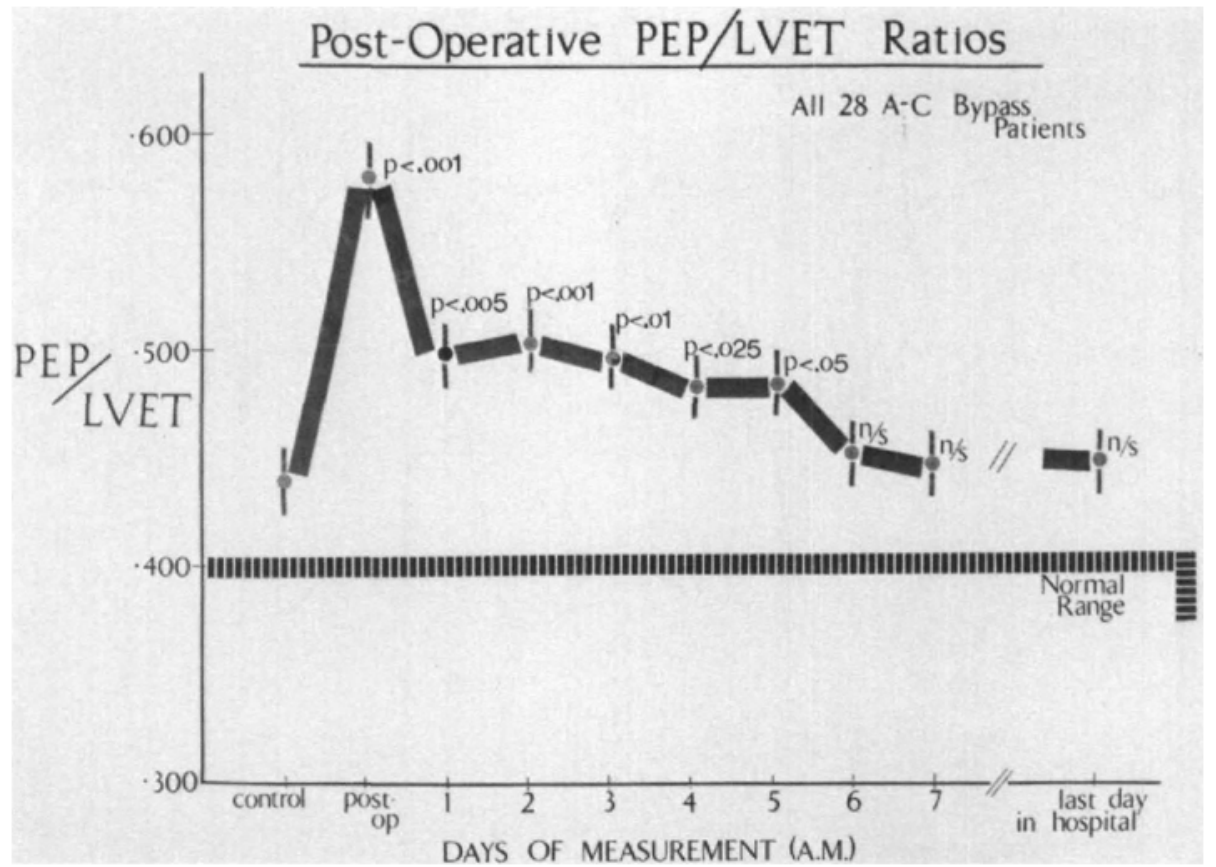

Frgure 2. Pattern of PEP/LVET changes after aorto-coronary bypass surgery in all 28 patients. Daily post-operative values in each patient are compared to pre-operative measurements.

post-operative measurement is highly significant in all patients (Figure 2). The maximal elevation of PEP/LVET ratio occurs in the initial 48 hours post-operatively. During hospitalization the PEP/LVET ratio returns to the control value, but does not enter the normal range.

\section{Pattern of $\mathrm{QS}_{2} I$ changes}

A shortening of the $\mathrm{QS}_{2} \mathrm{I}$ (total electromechanical systole corrected for heart rate) has been shown by others to correlate with an increased level of urinary catecholamine excretion ${ }^{8}$ ( Table III). $\mathrm{QS}_{2} \mathrm{I}$ is markedly shortened from the control value throughout the duration of hospitalization of our patients (Figure 3). This shortening is maximal during the first five post-operative days and did not return to pre-operative values by the time of discharge from hospital.

\section{Pattern of LEVTI changes}

The left ventricular ejection time corrected for heart rate (LVETI) has been shown to correlate well with the stroke volume. ${ }^{0}$ The LVETI decreased significantly in our patients and remained low throughout their hospitalization (Figure 4).

\section{Comparison of groups}

Groups A and B (eight patients in each group) represent distinctly different patient populations (Table I). Group A patients, with normal pre-operative ejection fractions, (mean $71 \pm 3.4$ per cent) were also found to have a mean pre- 


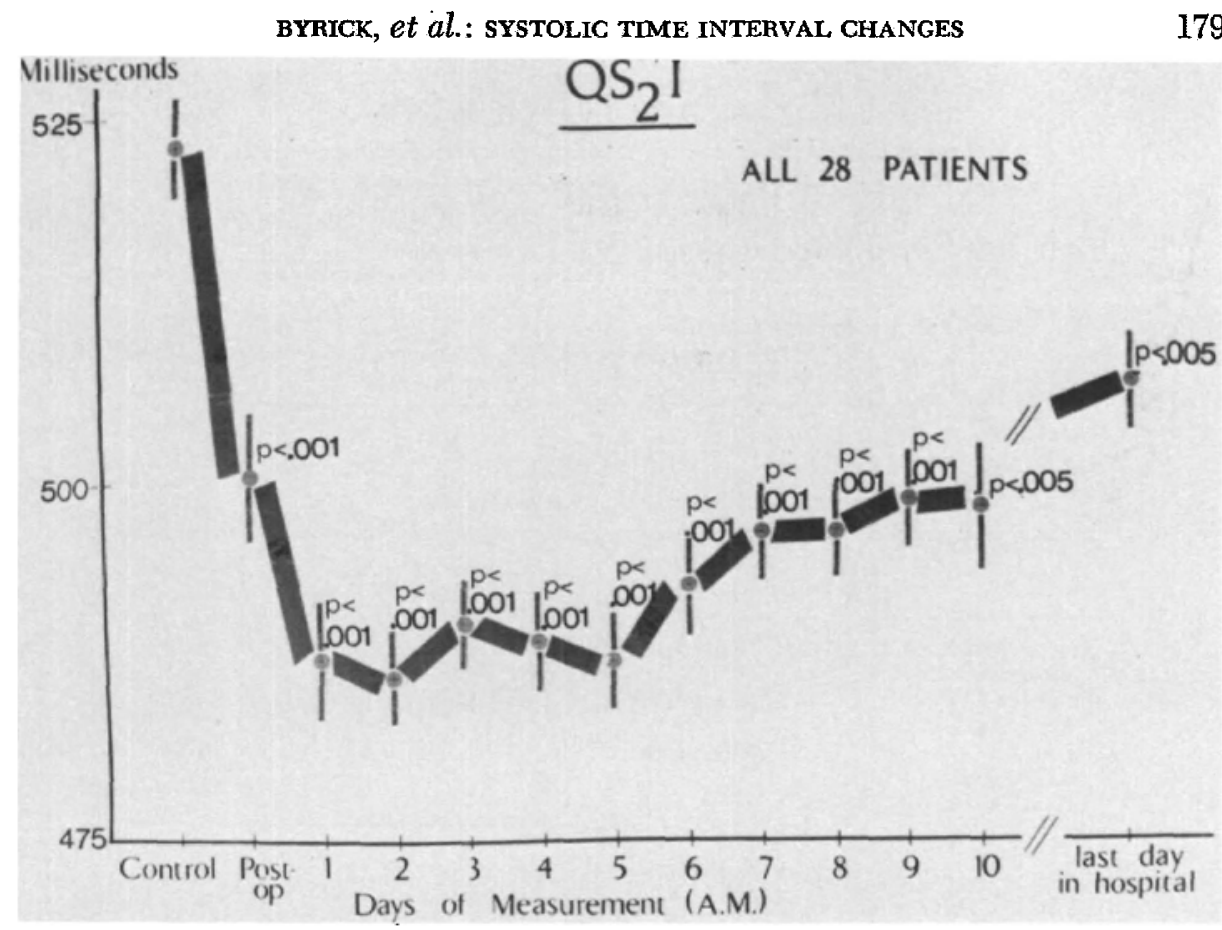

Frgune 3. Daily changes in $Q S_{2} I$ reflecting increased adrenergic tone in patients in the post-operative period.

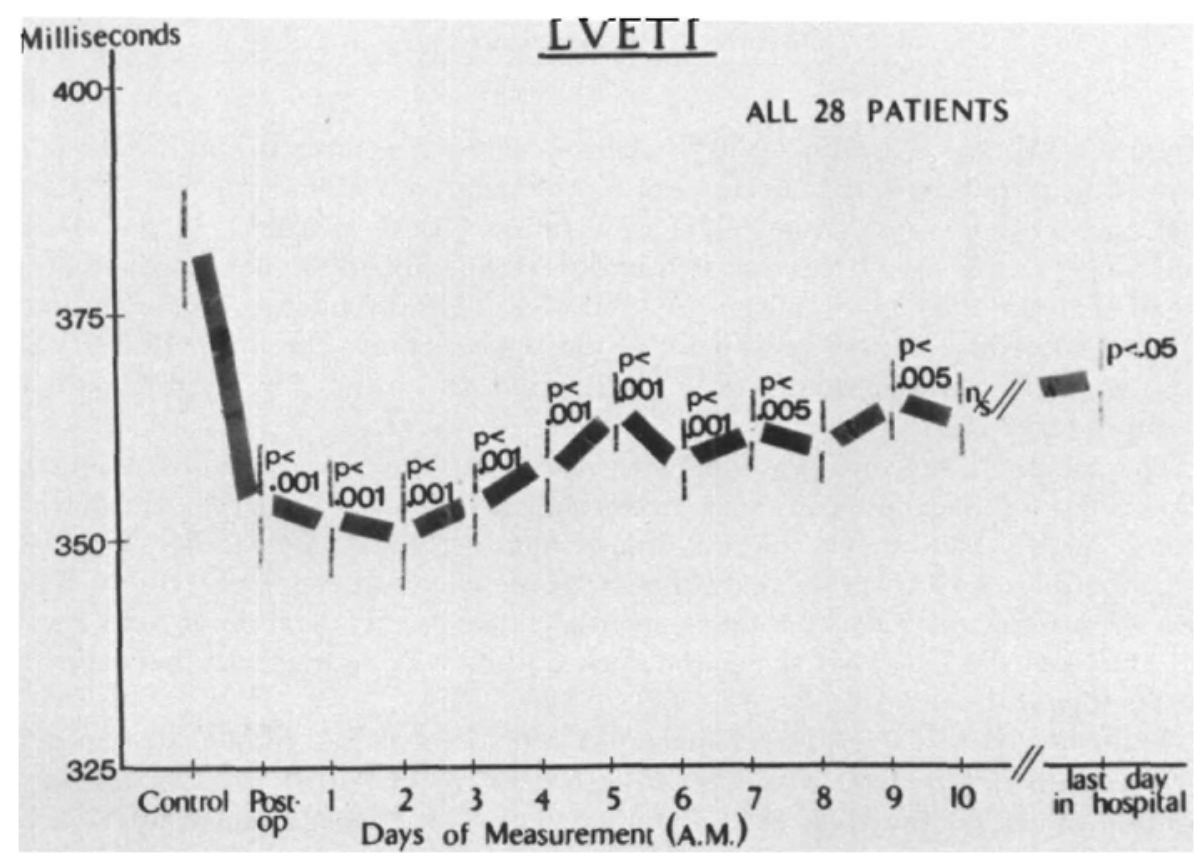

FIGURE 4. Daily changes in LVETI after aorto-coronary bypass surgery reflecting decrease in stroke volumes. 
TABLE I

Control Indices of Ventricular Performance

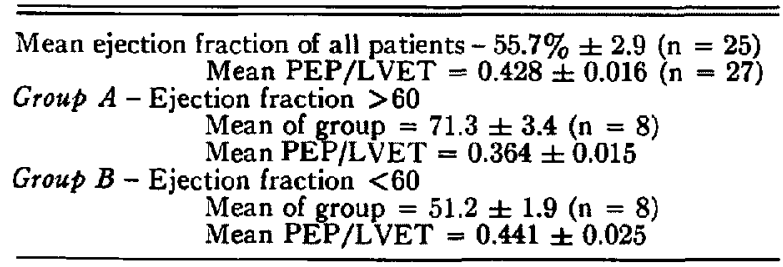

TABLE II

COMPARABILITY OF GROUPS

\begin{tabular}{|c|c|c|c|}
\hline & Group A & Group B & $\begin{array}{l}\text { Statistical } \\
\text { Difference }\end{array}$ \\
\hline $\begin{array}{l}\text { No. of vessels } \\
\text { Grafted }\end{array}$ & $2.38 \pm 0.26$ & $2.0 \pm 0.33$ & $\mathrm{n} / \mathrm{s}$ \\
\hline $\begin{array}{c}\text { Time on C.P. } \\
\text { Bypass }\end{array}$ & $101.38 \pm 17.28$ & $77.25 \pm 11.17$ & $\mathrm{n} / \mathrm{s}$ \\
\hline $\begin{array}{l}\text { Time of } \\
\text { Myocardial } \\
\text { Anoxia (min) }\end{array}$ & $21.06 \pm 2.67$ & $17.25 \pm 4.14$ & $\mathrm{n} / \mathrm{s}$ \\
\hline
\end{tabular}

TABLE III

Relationship of STI to Ventricular Function

1. PEP/LVET reciprocally $\alpha$ ventricular function

2. $Q S_{2} I$ reciprocally $a$ adrenergic activity

3. LVETI directly $\alpha$ stroke volume

operative PEP/LVET ratio $(0.364 \pm 0.015)$ within the normal range. Group $B$, consisting of patients with an abnormal pre-operative ejection fraction, (51.2 \pm $1.9)$ had mean pre-operative PEP/LVET ratios, $(0.441 \pm 0.025)$, in the abnormal range, that is more than one standard deviation above the normal population mean of $0.345 \pm 0.036$ established by Weissler. Thus although the patients were divided according to their pre-operative ejection fractions, the mean PEP/LVET ratio of Group $B$ was significantly higher than the mean PEP/LVET ratio of Group A ( $p<0.025)$.

The comparability of the groups with respect to other factors which might be expected to influence ventricular performance is shown in Table II. SeabraComes, et al. ${ }^{10}$ have shown that the time of total myocardial anoxia does correlate with the degree of ventricular dysfunction following surgery. However, in these two groups the periods of total myocardial anoxia, the number of vein grafts inserted and the length of the pump runs do not vary significantly between the two groups.

The pattern of PEP/LVET changes in Groups A and B is plotted in Figure 5. The patients in Group A, with normal pre-operative PEP/LVET ratios, return to control values on the third post-operative day. The patients in Group B, with abnormal control ratios return to control values by the fourth post-operative day, but do not approach the normal range. Both groups follow the same basic pattern 


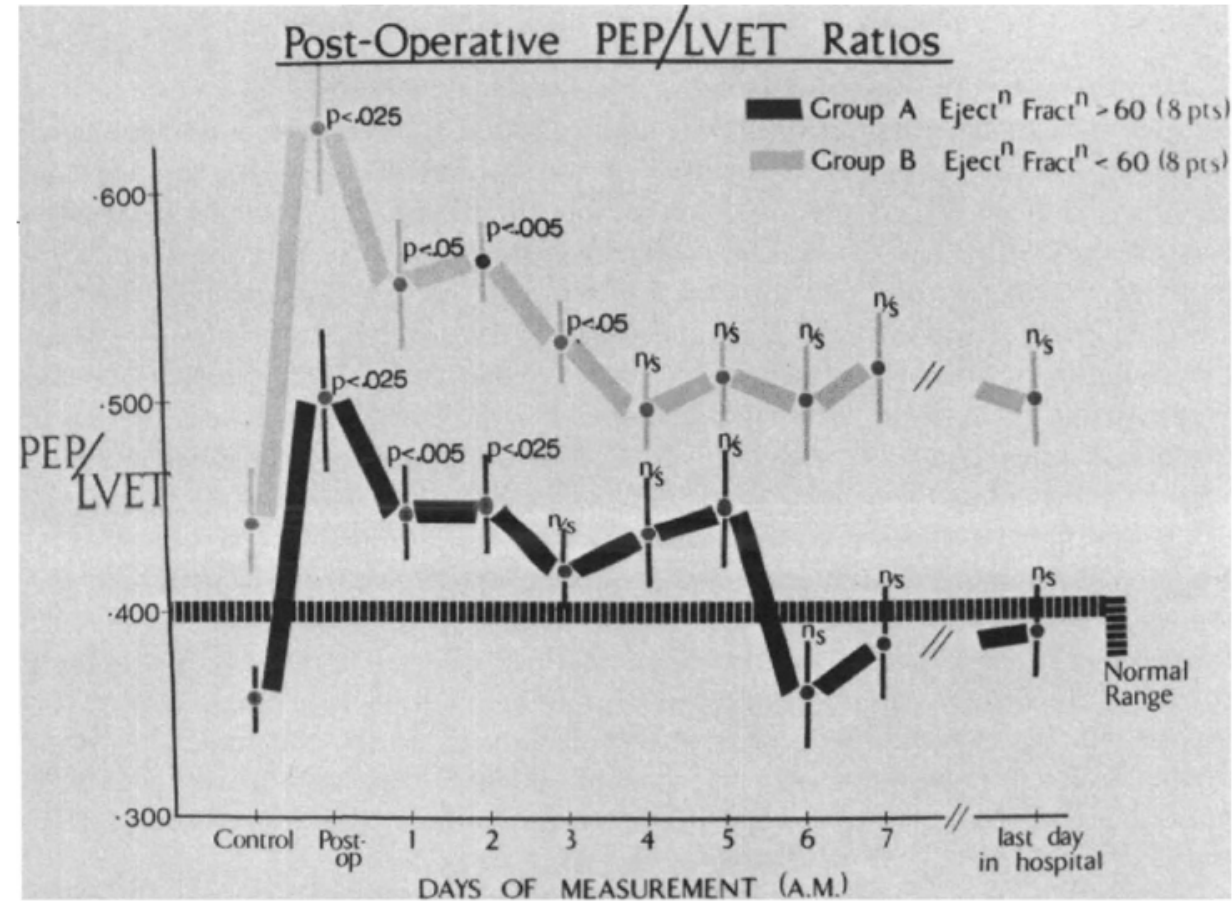

Frgure 5. Pattern of changes in PEP/LVET in patients with normal indices of ventricular contractility (Group A) as compared to patients with abnormal indices (Group B).

seen in all 28 patients; that is, the maximal ventricular dysfunction is seen in the first 48 post-operative hours in each group.

\section{Changes in pre-load and after-load}

Changes in pre-load and after-load may affect systolic time intervals as they do any other measurement of heart performance and we had to evaluate the importance of these factors in causing the marked change in intervals from the preoperative to the post-operative period. Consequently, we measured the change in pulmonary capillary wedge pressures pre-operatively and post-operatively and correlated these with simultaneous changes in the PEP/LVET ratio in nine of our patients on 17 different occasions. We found no significant statistical correlation ( $r=0.16)$ between changes in the wedge pressure (pre-load) and changes in the PEP/LVET ratios. Similarly, the change in after-load as represented by systemic vascular resistance (S.V.R.) was calculated from values of cardiac output measured by dye dilution, mean arterial pressure and central venous pressure. The S.V.R. was assessed in seven patients on eighteen different occasions. The change in S.V.R from the pre-operative value to subsequent post-operative values was correlated with simultaneous changes in PEP/LVET ratios. No significant correlation was demonstrable between the PEP/LVET ratios, and the after-load as measured by the S.V.R. $(r=0.41)$. However, when a three variable multiple linear regression was carried out, the change in PEP/LVET did vary significantly with simultaneous changes in P.C.W.P. and S.V.R. $(r=0.703 ; n=13, p=0.01)$. 


\section{Discussion}

The use of systolic time intervals as a daily record of ventricular performance following coronary artery surgery has demonstrated significant dysfunction in all 28 patients. The eight patients in Group A were separated on the basis of normal ejection fractions by invasive catheterization techniques. They could have been separated equally well on the basis of non-invasive systolic time intervals. Similarly, Group B patients had abnormal ventricular performance as measured by ejection fraction and PEP/LVET ratios. Garrard, et al. ${ }^{11}$ have previously shown that a highly significant relationship exists between PEP/LVET ratios measured non-invasively, and left ventricular ejection fraction measured invasively. Thus, pre-operative systolic time intervals could provide the anaesthetist with a convenient index of myocardial competence.

The ability of systolic time interval measurements to reflect altered ventricular function has not been used previously to monitor patients following anaesthesia and surgery on a daily basis. Matlof ${ }^{12}$ demonstrated on elevation of the PEP/LVET ratio at day seven following $\mathrm{A}-\mathrm{C}$ bypass procedures. He attributed this dysfunction to the acute deleterious effects of cardio-pulmonary bypass and temporary coronary inflow occlusion (time of myocardial anoxia) during surgery, Our study demonstrates a more rapid return to normal indices in patients (Group A) with normal pre-operative values. This difference probably relates to different patient populations studied.

There are several other factors which may be altered following surgery. Digitalis and increased adrenergic activity tend to shorten the PEPI., QS'I, and the LVETI. ${ }^{8}$ The effects of digitalis or beta receptor stimulation may mask the presence of diminished left ventricular performance. Thus, in spite of digitalization and the increased level of circulating catecholamines ${ }^{13,14}$ which follow surgery, the effects of left ventricular dysfunction predominate.

The influence of pre-load and after-load must be considered in the interpretation of all indices of myocardial contractility. ${ }^{15}$ The effects of pre-load and after-load on STI are extensively reviewed by Weissler. ${ }^{6,7}$ The use of a three variable multiple linear regression did demonstrate a significant relationship between the change in PEP/LVET and simultaneous changes in S.V.R. and mean pulmonary capillary wedge pressure. This relationship, which was not unexpected, does not detract from the fact that left ventricular performance is significantly depressed. The decrease in LVETI demonstrated reflects a decrease in stroke volume. This decrease in ventricular performance may be secondary to changes in pre-load, and after-load and/or contractility. Further investigation is underway to elucidate the importance of each of these three factors in the ventricular dysfunction which follows A.C. bypass.

The effects of anaesthesia are not thought to be responsible for the prolonged period of ventricular dysfunction demonstrated to follow surgery. Anaesthetic induced ventricular depression has been demonstrated by Prys-Roberts, et al. ${ }^{16}$ Blackburn, et al. ${ }^{17}$ have demonstrated a decrease in LVET and $Q S_{2}$ and a lengthening of the PEP by anaesthetic agents during induction, but no prolonged effect was found. Recently the narcotic-muscle relaxant anaesthetic technique has been 
found to produce less pronounced elevation of the PEP/LVET ratio than halothane in patients with heart disease. ${ }^{18}$

Our data agree with Matlof, et al. ${ }^{12}$ that since patients in Group A had normal indices prior to surgery, it is not surprising that no improvement from this value is found post-operatively. The patients in Group B, however, had poor pre-operative function demonstrated by both invasive and non-invasive techniques. No improvement from the control value is noted in either group prior to leaving hospital. Both Matlof ${ }^{12}$ and Johnson ${ }^{19}$ have reported improvement in the PEP/LVET ratios at two and three months respectively following coronary revasculatization.

The $\mathrm{QS}_{2}$ interval has been previously related to the 24-hour urinary catecholamine excretion. ${ }^{8}$ Thus, the extent of shortening of $\mathrm{QS}_{2} \mathrm{I}$ (Table III) probably reflects the extent of adrenergic activity in our patients following aorto-coronary bypass procedures. Our study confirms the work of Boudoulas, et al. ${ }^{20}$ who found marked shortening of the $\mathrm{QS}_{2} \mathrm{I}$ two weeks following surgery, associated with increased excretion of urinary catecholamines. Thus, systolic time intervals may provide an index of adrenergic tone in patients following surgery.

The anaesthetist is primarily concerned with patient care in the immediate post-operative period. An elevation of left atrial hydrostatic pressure secondary to left ventricular dysfunction has been shown to be the prime determinant of postoperative lung water accumulation. ${ }^{21}$ Hence, any improvement in ventricular function following surgery may reduce pulmonary complications.

The ability of STI measurements to reflect altered ventricular performance demonstrates the prospective value of this index in evaluating groups of patients. The use of STI by anaesthetists had been relatively limited. ${ }^{10,17}$ However, a recent report ${ }^{18}$ of a computerized system for on-line detection of systolic time intervals in the operating room reflects a renewed interest in this index as a monitor. The major criticism of the use of STI as a monitoring device is the lack of specificity of the measured changes. The effects of various physiological and pharmacological factors on STI has been well documented.6.7 These studies have shown that the $\mathrm{PEP} / \mathrm{LVET}$ ratio is a very sensitive, though non-specific measure of left ventricular performance. Our study demonstrates that pre-load and after-load should be simultaneously measured when this index is used to evaluate the effects of anaesthetic and surgical techniques.

The fact that this measurement is non-invasive and easy to perform increases the scope of its application. The lack of specificity of changes in systolic time intervals makes the interpretation in any single case more difficult than estimating general patterns of ventricular dysfunction in groups of patients.

\section{Conclusion}

Pre-operative assessment of PEP/LVET ratio was as reliable as invasively measured ejection fraction in separating patients with normal ventricular performance from those with abnormal indices.

Our study demonstrates significant impairment of ventricular performance following aorto-coronary bypass procedures. The duration of this dysfunction is 
between two and five days following operation and is maximal in the first 48 hours. Meaningful interpretation of systolic time interval changes requires measurement of pre-load and after-load. Changes in these variables account for at least some of the increase in PEP/LVET ratio noted in our study. On the basis of a shortened $\mathrm{QS}_{2} \mathrm{I}$ these patients are thought to exhibit increased adrenergic activity for the entire period of their hospitalization.

\section{RÉSUMÉ}

Le rapport PEP/LVET (Pre-Ejection Period/Left Ventricular Ejection Time) se compare favorablement à la mesure de la fraction d'éjection - une technique invasive - lorsque l’on veut déterminer si un malade présente une fonction ventriculaire normale ou anormale.

Notre étude a mis en évidence une dysfonction ventriculaire gauche significative après chirurgie aorto-coronarienne. Cette dysfonction dure de deux à cinq jours et elle se manifeste à son maximum au cours des premières 48 heures.

L'interprétation des changements observés dans la mesure des intervalles systoliques doit être faite à la lumière des modifications de la pré et de la post-charge; leur mesure est donc nécessaire. Les modifications de ces paramètres sont en partie responsables de l'augmentation du rapport $\mathrm{PEP} / \mathrm{LVET}$ observé chez nos malades.

Le raccourcissement des intervalles systoliques noté chez nos patients est attribuable à l'augmentation de l'activité adrénergique, observée tout au long de l'hospitalisation.

\section{ACKNOWLEDGEMENTS}

The authors wish to acknowledge the assistance of Dr. B. Goldman and Dr. J. Gunstensen (Toronto General Hospital) whose patients were studied, and of Mr. Colin Kay in the statistical evaluation of data.

We also thank Dr. Arthur Scott, Dr. Alan Laws and Dr. R.A. Gordon for their assistance in reviewing the manuscript.

\section{REFERENCES}

1. Conn, P.R., et al. Ejection fraction and prognosis in cardiac surgery. Am. J. Cardiol. 34: 140-141 (1974).

2. Martin, E.C., Shaver, J.A., Thompson, M.E., et al. Direct correlation of external systolic time intervals with internal indices of left ventricular function in man. Circulation, SLIV, $419-431$ (1971).

3. Mailho', J.W., Sandeey, H., \& Harruson, D.C. Left ventricular function following coronary bypass surgery. Circulation 44, Suppl. II, 196 (1971).

4. ReEs, G., Bnistow, J.D., KremKau, E.L., et al. Influence of aorto-coronary bypass surgery on left ventricular performance. New Eng. J. Med. 284: 1116 (1971).

5. Bounoulas, H., Lewis, R.P., \& Karayannacos, P.E. Effect of saphenous vein graft surgery upon left ventricular function. Am. J. Cardiol. (Abstract) 31: 123 (1973).

6. Weissler, A.M. Non-invasive cardiology. Grune and Stratton, New York. pp. 301 (1974).

7. Weissler, A. \& Gafrafd, C. Systolic time intervals in cardiac disease (I) (II). Modern concepts of cardiovascular disease (January 1971).

8. Lewis, R.P., Boudoulas, H., Fonester, W.F., et al. Shortening of electromechanical systole as a manifestation of excessive adrenergic stimulation in acute myocardial infarction. Circulation 46: 856 (1972). 
9. Weissler, A.M., Peeler, R.C., \& Roehli, W.H.J. Relationships between left ventricular ejection time, stroke volume, and heart rate in normal individuals and patients with cardiovascular disease. Am. Heart J. 62; 367 (1961).

10. Seabra-Gomes, R., Sutton, R., \& Parker, D.J. Left ventricular function after aortic valve replacement. British Heart J. 38: 491 (1976).

11 Garrard, C.L. Jr., Weissler, A.M., \& Dodge, H.T. The relationship of alterations in systolic time intervals to ejection fraction in patients with cardiac disease. Circulation 42: $455(1970)$.

12. Matlof, H., Hultchen, H.N., Pfeifen, J.F., \& Harrison, D.C. Cardiac function assessed by systolic time intervals after aorto-coronary saphenous vein bypass surgery. British Heart J. 35: 714 (1973).

13. Repogle, R., Levy, M., \& DeWALl, R.A., et al. Catecholamine and serotonin response to cardiopulmonary bypass. J. Thoracic and Cardiovasc. Surg, 44: 638 (1962).

14. Cooper, T., Jelinek, M., William, V.T., et al. Biochemical studies of myocardium and blood during extracorporeal circulation in man. Circulation 31-32, Suppl. I, 1-144 (1965).

15. Quinones, M.A., GaAsch, W.H., \& Alexander, J.K. Influence of acute changes in pre-load and after-load, contractile state and heart rate on ejection and isovolumic indices of myocardial contractility in man. Circulation 53: 293 (1976).

16. Prys-Robents, C., Gersh, B.J., Baкen, A.B., et al. The effects of halothane on the interactions between myocardial contractility, aortic impedance, and left ventricular performance. Brit. J. Anaesth. 44: 634 (1972).

17. Blackrurs, J.P., Conway, C.M., Davies, R.M., et al. Valsalva responses and systolic time intervals during anaesthesia and induced hypotension. Brit. J. Anaesth. 45: 472 (1976).

18. Davchot, P.J., Rasmussen, J.P., Nicholson, D.H., et al. On line systolic time intervals during anaesthesia in patients with and without heart disease. Anaesthesiology 44: 472 (1976).

19. Johnson, A.D., O'Rouke, R.A., Karliner, J., et al. Effect of myocardial revascularization on systolic time intervals in patients with left ventricular dysfunction. Supp. 1 to Circulations, Vols. XLV and XLVI, 1-91 (May 1972).

20. Boudoulas, H., Lewis, R.P., VASKo, J.S., et al. Left ventricular function and adrenergic hyperactivity before and after saphenous vein bypass. Circulation 53:5 (1976).

21. Byнick, R.J., KAY, J., \& Nober, W.H. Extravascular lung water accumulation following coronary artery surgery. C.A.S.J. (In preparation.) 